\title{
Use of surface plasmon resonance for the measurement of low affinity binding interactions between HSP72 and measles virus nucleocapsid protein
}

\author{
Xinsheng Zhang ${ }^{1}$ and Michael Oglesbee ${ }^{1 *}$ \\ 1Department of Veterinary Biosciences, The Ohio State University, Columbus, Ohio 43210. \\ *To whom correspondence should be addressed: Michael Oglesbee, Department of Veterinary Biosciences, \\ The Ohio State University. 1925 Coffey Road, Columbus, OH 43210. Phone: 614-292-9672. Fax: 614-292- \\ 6473. Email: Oglesbee.1@osu.edu
}

Submitted: June 2, 2003; Revised: August 6, 2003; Accepted: August 7, 2003; Published: September 5, 2003

Indexing terms: Surface plasmon resonance technology; Measles virus.

\begin{abstract}
The $72 \mathrm{kDa}$ heat shock protein (HSP72) is a molecular chaperone that binds native protein with low affinity. These interactions can alter function of the substrate, a property known as HSP-mediated activity control. In the present work, BIAcore instrumentation was used to monitor binding reactions between HSP72 and naturally occurring sequence variants of the measles virus (MV) nucleocapsid protein $(\mathrm{N})$, a structural protein regulating transcription/replication of the viral genome. Binding reactions employed synthetic peptides mimicking a putative HSP72 binding motif of N. Sequences were identified that bound HSP72 with affinities comparable to wellcharacterized activity control reactions. These sequences, but not those binding with lesser affinity, supported HSP72 activity control of MV transcription/replication. BIAcore instrumentation thus provides an effective way to measure biologically relevant low affinity interactions with structural variants of viral proteins.
\end{abstract}

\section{INTRODUCTION}

The $70 \mathrm{kDa}$ family of heat shock proteins contains important intracellular molecular chaperones. The molecules may either be constitutively expressed or induced under conditions of cellular stress such as fever or viral infection. HSP72 is the major inducible member of the $70 \mathrm{kDa}$ family and can bind both denatured and native protein substrates. Typically, the HSP72 binding motif can be defined by a linear sequence of 7 amino acids containing hydrophobic side groups or aromatic rings (1). Incorrectly folded and/or denatured proteins have increased exposure of highly hydrophobic sequences on their surface. Association between HSP72 and these malfolded proteins can delay or prevent their self-aggregation and thereby promote proper folding, a function known as HSP72-mediated protein stability control. The other function of HSP72 in substrate binding is known as activity control. In this capacity, HSP72 interacts with native proteins through domains containing clusters of hydrophobic amino acid side groups on the surface (2). The interaction can help to stabilize or alter conformation and thus function of the substrate, particularly if the binding target resides within an intrinsically disordered domain (3). For both types of interactions, association and dissociation of substrate molecules is regulated by ATP-ADP exchange in the nucleotide binding site of HSP. This property is illustrated by activity control binding reactions involving E.coli DnaK, the prokaryotic analogue of HSP72, and the transcription factor $\delta^{32}$ (2). In the presence of ATP, the HSP72 substrate-binding pocket is open and substrate association/dissociation is rapid. In the

C2003. Biological Procedures Online. Published in Biological Procedures Online under license from the author(s). Copying, printing, redistribution and storage permitted. 
presence of ADP, the pocket is closed and substrate dissociation is slow, decreasing the $K_{D}$ for the binding reaction. Cycles of ADP-ATP exchange are thus the basis for the highly reversible nature of HSP-substrate interactions. Overall, affinity between HSP and substrate is greater in stability control reactions compared to activity control reactions. Typical affinities between HSP72 and unfolded protein substrate are in the $\mathrm{nM}$ range. In contrast, DnaK binding affinity for native proteins is typically in the $\mu \mathrm{M}$ range, with reaction $\mathrm{K}_{\mathrm{D}}$ 's reported between $0.01-1 \mu \mathrm{M}$ (4, 5) and 1-50 $\mu \mathrm{M}(6)$.

Studies have demonstrated HSP72's interaction with viral structural proteins in a manner that promotes viral gene expression (7-9). Previous work from our laboratory documented a role for HSP72 in the measles virus (MV) and canine distemper virus (CDV) life cycle. MV and CDV are negative-strand RNA viruses within the morbillivirus genus of Paramyxoviridae. These viruses have a helical ribonucleoprotein (RNP) core particle consisting of the single-stranded RNA genome packaged by the nucleocapsid protein $(\mathrm{N})$. This RNP serves as template for the virus-encoded RNA-dependent RNA polymerase. HSP72 reversibly associates with the CDV and MV RNP in an ATPdependent manner, resulting in increased RNP transcriptional activity (10-13). The phenomenon is consistent with HSP72mediated activity control since the HSP72 substrate is preformed and binding results in altered function of the substrate. Several lines of evidence support $\mathrm{N}$ protein as the target for HSP72 binding. First, confocal immunofluorescence microscopy of infected cells show co-localization of HSP72 and N protein but not other viral core proteins (14). Secondly, the stoichiometry of RNP-HSP72 interaction indicates a target of high copy number that exceeds all but that of the $\mathrm{N}$ protein. Finally, $\mathrm{N}$ protein is the determinant of RNP structure and HSP72-RNP binding alters RNP morphology (12). The $\mathrm{N}$ protein domain mediating HSP72 binding should be located on the carboxyl terminus since only the carboxyl terminus of $\mathrm{N}$ is exposed when incorporated into the RNP (26). An HSP72 binding motif was identified within this region represented by the sequence $\mathrm{Y} \mathrm{N} \mathrm{D}$ R N L L (15). This sequence has typical elements that predict binding for all $70 \mathrm{kDa}$ heat shock protein family members, including HSP72, HSP73, and BiP (HSP78) (1). The algorithm developed for BiP shows a preference for substrates containing aromatic (Y) and hydrophobic (L) amino acids while basic amino acids $(\mathrm{R})$ are tolerated. In fact, inclusion of basic residues confers selectivity for HSP72 binding (16). Acidic residues (D) may be present, although they diminish binding affinity, while noncharged residues $(\mathrm{N})$ have neither positive nor negative impact upon binding (16). The region of the MV $\mathrm{N}$ protein encompassing this binding motif is intrinsically disordered (17), providing a mechanistic basis by which HSP72-N protein binding events could alter $\mathrm{N}$ protein conformation and thus function as template for viral RNA synthesis.

The objective of the present study was to employ surface plasmon resonance technology in the identification of MV N protein carboxyl terminal sequences that engage in low affinity interactions with HSP72, correlating results of binding studies to those that measure functional interactions. Conventional methods of measuring binding interactions were considered poorly suited to the analysis of low-affinity HSP72-substrate affinity control reactions, where the affinity of HSP72 for various substrates is compared. Use of chromatographic co-purification or co-immunoprecipitation has not been reported in such an application, possibly because of the limited sensitivity of these methods. Solid phase binding of HSP72 to cellulose-bound peptide was used to screen the binding targets of DnaK (18). Peptide co-crystallization was also used to identify the motifs recognized by DnaK (19). Use of a yeast two hybrid system would appear amenable to such an application, although this has not been described. These latter methods are labor intensive and/or better suited to describing presence or absence of specific binding rather than characterization of binding reaction constants that distinguish amongst closely-related substrates. Use of surface plasmon resonance technology that is the basis for Biomolecular Interaction Analysis (BIAcore) instrumentation represents the most expedient approach by which low-affinity protein interactions can be measured in real-time. With BIAcore, one interaction partner is conjugated on the surface of a sensor chip (ligand) and the other binding partner flows over the surface (analyte), facilitating the analysis of binding differences between multiple analytes and a single ligand. The approach is based on an optical detection system that monitors real-time changes in protein mass on the sensor surface. Binding events result in changes in protein mass that, in turn, alter surface plasmon resonance, an electro-magnetic phenomenon that dampens the intensity of light reflected off of the surface of the sensor chip at a specific angle (i.e., resonance angle). The change of resonance angle resulting from analyte-ligand interaction is measured in resonance units $(\mathrm{RU})$ and plotted in sensorgrams as a function of time. A response of 1000 RU corresponds to a change of about 1 $\mathrm{ng} / \mathrm{mm}^{2}$ in surface protein concentration. Affinity values of analyte-ligand binding are then derived through fitting the resultant sensorgrams to those in a bank of well-characterized binding reactions. A high quality fit between unknown and standard reactions is the basis for identifying reaction constants that include on rate $\left(k_{a}\right)$, off rate $\left(k_{d}\right)$, and a calculated equilibrium dissociation constant $\left(\mathrm{K}_{\mathrm{D}}\right)$.

Synthetic peptides containing carboxyl terminal sequences of the $\mathrm{N}$ protein were used as analyte in binding reactions with immobilized HSP72. Use of peptide instead of monomeric $\mathrm{N}$ protein $\left(\mathrm{N}^{0}\right)$ reflects the difficulty in obtaining $\mathrm{N}^{0}$ in pure form (i.e., without $\mathrm{P}$ protein) and the fact that $\mathrm{N}^{0}$ contains extensive hydrophobic regions in the amino-terminal three fourths of the molecule that predict HSP72- $\mathrm{N}^{0}$ interaction but are likely irrelevant to RNP-HSP72 binding since these regions are inaccessible when $\mathrm{N}$ is incorporated into the RNP. Peptides 15 amino acids in length were based upon the Edmonston MV sequence, the strain upon which vaccines are based. Variant peptides were also designed to incorporate one or two modifications in the HSP72 binding motif that reflect naturally occurring sequence polymorphisms, including $\mathrm{N}$ to $\mathrm{D}$ and/or $\mathrm{L}$ to $\mathrm{P}$ substitutions. Positive and negative controls for specific binding to HSP72 included a fifteen amino acid peptide representing the HSP72 binding motif of P53 (20) and a fifteen 
amino acid myelin basic protein-derived peptide (21), respectively. Relevance of peptide-HSP72 interaction analysis to RNP-HSP72 binding was defined by examining the ability of free peptide to inhibit RNP-HSP72 interaction on BIAcore sensors. The contribution of the carboxyl terminus of $\mathrm{MV} \mathrm{N}$ protein in mediating HSP72 binding was further documented using intact MV RNP and MV RNP with the carboxyl terminus removed in the binding reactions. Our results showed that the BIAcore approach readily identified naturally occurring sequence polymorphisms in the carboxyl terminus of MV $\mathrm{N}$ protein that exhibited reduced binding to HSP72, a result correlated to loss of activity control in functional assays.

\section{MATERIALS AND METHODS}

\section{Peptide analytes}

Synthetic peptides were 15 amino acids in length. Peptide N represented the extreme carboxyl terminus of the Edmonston MV N protein. Peptide N4D contained an asparagine (N) to aspartic acid (D) substitution at the fourth residue upstream from the carboxyl terminus. The sequence is characteristic of $\mathrm{MV}$ central nervous system isolates belonging to genotypes C1, C2, D1, E, and F (22). Peptide N3P4D contained an additional leucine $(\mathrm{L})$ to proline $(\mathrm{P})$ substitution and is also based upon a MV central nervous system isolate belonging to the $\mathrm{C} 1$ genotype. The P53 peptide represented a 15 amino acid sequence previously shown to mediate binding between P53 and HSP72 (20). The myelin basic protein (MBP) peptide contained a 15 amino acid sequence that was not predicted to bind HSP72 using the BiP algorithm. All peptides were custom synthesized (Genemed Synthesis Inc, San Francisco, CA) with the exception of MBP peptide. The latter was purchased from a commercial source (Sigma, St. Louis, MO). All peptides were purified to greater than $95 \%$ purity by high-pressure liquid chromatography and characterized by mass spectral analysis. Complete peptide sequences were as follows:

$\begin{array}{ll}\text { N: } & \text { DTDTPIVYNDRNLLD } \\ \text { N4D: } & \text { DTDTPIVYNDRDLLD } \\ \text { N3PD: } & \text { DTDTPIVYNDRDPLD } \\ \text { p53: } & \text { STSRHKKLMFKTEGP } \\ \text { MBP: } & \text { YGSLPQKAQRPQDEN }\end{array}$

Binding reactions were performed in HBS-P running buffer ( 0.01 M HEPES pH 7.4, $0.15 \mathrm{M} \mathrm{NaCl}, 0.005 \%$ Surfactant P20) adjusted to a final concentration of $2.5 \mathrm{mM}$ MgAcetate and $2.5 \mathrm{mM}$ ATP (Disodium Salt, Sigma). Buffer was fully degassed and filtered before use. Lyophilized peptides were directly resuspended in running buffer to a concentration of $1 \mathrm{mM}$. Injection of peptides contained in running buffer minimized sensorgram bulk shifts caused by changes in buffer conditions on the sensor surface. Analyte concentration is used in rate constant calculations, making accurate analyte concentration measurements essential. In the present work, peptide mass before reconstitution was determined on a Mettler H54AR scale (Product of Metter-Toledo Inc., Columbus, $\mathrm{OH}$ ) to an accuracy of $0.01 \mathrm{mg}$. To prevent analyte loss as a consequence of adsorption to the walls of microfuge tubes or pipette tips, all items used in the manipulation of samples were coated with Sigmacote (Sigma), a chlorinated organopolysiloxane reagent.

\section{Viral ribonucleoprotein analytes}

MV RNP was purified as previously described (13). Briefly, infected Vero cells were harvested at the time of maximum virus induced cytopathic effect. The ATP concentration of cell lysates was adjusted to a final concentration of $2.5 \mathrm{mM}$ to assure dissociation of HSP72 from RNP particles so that subsequent analysis of binding reactions between RNP and HSP72 could be performed without interference from pre-formed HSP72-RNP complexes (23). Viral RNP was purified from clarified cytoplasmic extracts by $\mathrm{CsCl}$ isopycnic density centrifugation at $27,000 \mathrm{xg}$ for 2 hours at $4^{\circ} \mathrm{C}$. RNP-containing gradient fractions were pooled and dialyzed against HBS-P buffer for use in binding analyses. RNP particles, when intact, are over $1 \mu \mathrm{m}$ in length, although actual length is quite heterogeneous due to fragmentation that occurs during isolation (24). The combination of large and small particle sizes can induce aberrations (i.e., spikes) in the sensorgrams. Accordingly, RNP preparations were sheared by vigorously vortexing solutions for $1 \mathrm{~min}$. Previous electron microscopic evaluation of RNP preparations showed that such manipulation reduces the range in particle length, resulting in a smaller mean, a smaller standard deviation of the mean, and a reduction in the amplitude of sensorgram spikes (Oglesbee et al., unpublished observation, 25). RNP total protein was characterized by $12 \%$ SDS-PAGE. The $\mathrm{N}$ protein concentration was established by comparing its Coomassie staining intensity to that of a standard curve created with 0.075 , $0.15,0.3,0.6$, and $1.2 \mu \mathrm{g}$ bovine serum albumin. The protein composition of nucleocapsid isolated in this manner is $88 \% \mathrm{~N}$ protein, $9 \% \mathrm{P}$ protein, and $1 \% \mathrm{~L}$ protein by mass based upon relative Coomassie staining intensities.

RNP containing $\mathrm{N}$ protein monomers lacking the carboxyl terminal $15 \mathrm{kDa}$ was generated by digestion with Staphylococcus aureus V8 protease (Pierce, Rockford, IL). Such digestion preserves the amino terminal $45 \mathrm{kDa}$ portion of the $\mathrm{N}$ protein monomer that is essential for RNP structural integrity (26). Enzyme was added to RNP total protein in HBS-P running buffer to a final concentration of $4.8 \mathrm{U} / \mathrm{ml}$. Reactions were adjusted to an $\mathrm{N}$ protein concentration of $80 \mathrm{nM}$. Digests were performed at $37^{\circ} \mathrm{C}$ for $20 \mathrm{~min}$. Cleavage of $\mathrm{N}$ protein was confirmed and the concentration determined by SDS-PAGE using the BSA standard as previously described. The protease was not separated from RNP in order to avoid excessive sample manipulation, an approach made feasible due to the negligible contribution of V8 protease to the total sample protein (i.e., < $1 \%)$. The presence of $\mathrm{V} 8$ protease in the binding reactions did 
not affect HSP72 immobilization levels on the sensor surfaces nor was HSP72 binding activity affected, based upon subsequent analysis of characterized binding reactions between HSP72 and peptide analytes. Based upon these observations, V8 protease did not cause significant degradation of HSP72 ligand.

\section{Preparation of BIAcore sensor surfaces}

To prepare HSP72 for immobilization, an aqueous HSP72 solution (1.1 $\mathrm{mg} / \mathrm{ml}$ recombinant human HSP72)(Stressgen Biotechnologies, Victoria, BC Canada) was dialyzed against Acetate buffer $5.0(10 \mathrm{mM}$ sodium acetate $\mathrm{pH}$ 5.0) overnight using Slide-A-Lyzer cassettes with a $10 \mathrm{kDa}$ cut-off (Pierce Biotechnology, Rockford, IL). A range of HSP72 loading levels were resolved by 12\% SDS-PAGE and the signal intensities of Coomassie stained proteins quantitated by laser densitometry. The HSP72 concentration was determined through regression analysis of a standard curve generated with BSA as described above. The isoelectric point of HSP72 is 5.41 such that a net positive charge was imparted upon the protein in the $\mathrm{pH} 5.0$ acetate buffer. The positive charge, in turn, facilitated the electrostatic interaction between HSP72 and the carboxymethylated dextran matrix on the surface of the CM5 sensor chip. This preconcentration step was designed to maximize the final yield of covalently linked protein. Use of lower $\mathrm{pH}$ buffers were not used in order to avoid loss in biologic activity of the HSP72 ligand.

Covalent linkage of HSP72 to the dextran matrix was achieved by amine coupling (Amine Coupling kit, BIAcore Inc.). Activation of the carboxyl groups on the matrix was performed by adding a mixture of succinimide (NHS, $11.5 \mathrm{mg} / \mathrm{ml}$ in deionized water) and carbodiimide (EDC, $75 \mathrm{mg} / \mathrm{ml}$ in deionized water) to form active esters that react spontaneously with amine groups on the HSP72 molecules. The degree of HSP72 immobilization was achieved through manual injection of $5 \mu \mathrm{g} / \mathrm{ml}$ HSP72 pulses followed by continuous flow of HBS-P buffer at $10 \mu \mathrm{l} / \mathrm{min}$. Non-covalently bound HSP72 was generally eluted within 5 minutes, with the difference in sensorgram baseline between preand post-HSP72 injection representing the HSP72 immobilization level. After the desired level of immobilization was achieved, a $1 \mathrm{M}$ ethanolamine solution was injected to deactivate remaining active esters.

A total of 4 different binding surfaces or flow channels were prepared on each chip. Flow channel 1 (FC1) was activated with NHS/EDC and blocked with ethanolamine but no HSP72 was conjugated. The resultant FC1 was used as a negative control for non-specific interactions between analyte and sensor surfaces. Remaining flow channels contained different immobilization levels of HSP72. Twenty thousand RU of HSP72 (where 1,000 RU equals to $1 \mathrm{ng} / \mathrm{mm}^{2}$ of HSP72 on the surface) was used to establish the presence and specificity of peptide binding. The high immobilization levels were designed to generate large sensorgram deviations following binding by the relatively small peptide analytes. Ten thousand RU of HSP72 was used for the kinetic analysis of peptide binding reactions and to establish the specificity of HSP72-nucleocapsid binding. Two hundred fifty RU of HSP72 was immobilized for kinetic analysis of HSP72nucleocapsid binding reactions. Sensorgrams readily returned to baseline in the dissociation phase of the HSP72-analyte binding reactions, obviating the need for a sensor surface regeneration step.

\section{Binding reaction analysis}

Signal changes on the activated/blocked control channel were subtracted from the peptide-HSP72 or RNP-HSP72 binding interactions using in-line reference and the subtracted sensorgrams were analyzed. Since HSP72 has only a single peptide binding cleft per molecule, curves generated with serial analyte concentrations were applied globally to the 1:1 Langmuir binding model with or without correction for baseline drifting depending on baseline status. $\mathrm{Chi}^{2}$ and residual values were used to evaluate the quality of fit between the experimental data and individual binding models. Plots of residuals indicate the difference between the experimental and reference data for each point in the fit. The $\mathrm{Chi}^{2}$ value represents the sum of squared differences between the experimental data and reference data at each point.

\section{RESULTS AND DISCUSSION}

\section{Design rationale}

Peptides that mimic the carboxyl terminal 15 amino acids of the MV N protein were tested for their ability to bind HSP72. The BIAcore approach is based upon the ability to detect changes in mass on a sensor surface that, when corrected for non-specific interactions between the analyte in solution and unmodified sensor surfaces, reflect binding reactions with the immobilized ligand. Using the BIAcore optical detection system, binding of analyte having a large mass is more readily detected than binding of small analytes. Accordingly, optimal detection of binding events could be based upon use of HSP72 as analyte and peptide as ligand. The limitation of this approach is that it is not conducive to comparing binding reactions between HSP72 and multiple substrates. First, one would have to examine binding reactions between $\mathrm{HSP} 72$ and multiple levels of immobilized peptide to provide assurance that differences in calculated equilibrium dissociation constants reflected differences in peptide sequence and not differences in the level of immobilization between peptides. Secondly, use of purified recombinant HSP72 as analyte would be cost prohibitive considering the concentration ranges required for analysis, the volume of analyte solutions required, and the challenges to recovery of HSP72 without loss of binding activity following each run. Decline in HSP72 binding capacity with time was documented by comparing sensorgrams generated on a freshly prepared sensor and the same sensor following storage at $4^{\circ} \mathrm{C}$ for 4 days (Fig. 1). Loss of binding activity was not attributable to regeneration 
conditions used between binding reactions (i.e., conditions promoting complete remove of analyte prior to subsequent binding reaction analysis). In our experiments, addition of ATP to the running buffer helped return sensorgram baseline to prereaction values following peptide or RNP injections. Accordingly, there was no need to regenerate the surface using more harsh dissociation conditions (Fig. 2), and run-to-run variability in results recorded within a given experimental session was not significant. Peptide inhibition of RNP-HSP72 interaction is another way to indirectly monitor peptide-HSP72 interaction. This approach takes advantage of the large sensorgram shift when RNP segments bind the sensor, each segment composed of multiple $60 \mathrm{kDa} \mathrm{N}$ protein monomers. Use of RNP analytes is amenable to establishing the specificity of peptide-HSP72 interactions and defining binding reaction constants (27), however, we chose direct peptide-HSP72 interaction analysis since large amounts of peptide analyte were much more readily obtained than were RNP preparations fragmented to a range of particle sizes amenable to BIAcore analysis, making the direct analysis a much more expedient approach.

\section{Sensor selection and binding reaction conditions}

Using peptide as analyte, we were able to detect binding events by using peptides 15 amino acids in length versus the nominal seven amino acids that comprise the putative HSP72 binding motif, by optimizing reaction buffer conditions, and by increasing the density of HSP72 immobilized on the sensor chip. Increased peptide size facilitates detection of binding and improves peptide solubility. In addition to $2.5 \mathrm{mM}$ ATP, reaction buffers were supplemented with $2.5 \mathrm{mM}$ magnesium acetate and surfactant P-20. The $\mathrm{Mg}^{++}$was added to better mimic physiologic conditions supporting ATP/ADP-dependent HSP72-substrate interactions. Our results showed that inclusion of $\mathrm{Mg}^{++}$increased specific binding over background. Peptide interaction with irrelevant ligand (i.e., $\operatorname{IgG}$ ) was not influenced by $\mathrm{Mg}^{++}$whereas peptide binding to HSP72 was significantly increased by the inclusion of $\mathrm{Mg}^{++}$in the reaction buffer (Fig. 3). Surfactant P-20 was included in the buffer system to help reduce analyte aggregation. A broad range of ligand densities was made possible through use of the CM5 sensor chips. The surface of these chips has long dextran arms to which ligand can be covalently linked. The longer the arms, the greater the potential ligand density. Preliminary studies examined use of surfaces lacking a dextran matrix (i.e., C1 chip) and sensors with short dextran linker arms (i.e., F1 chip). Both of these conditions proved unsuitable for the analysis of HSP72-peptide binding. The C1 chip did not support levels of HSP72 immobilization that allowed detection of binding by the small peptide analytes. The F1 chip supported HSP70 immobilization levels comparable to that used on CM5 chips in subsequent kinetic analyses, however, the background reactivity between peptide and activated/blocked flow channels was unacceptably high.

\section{Peptide binding specificity}

High HSP72 immobilization densities were used to established specificity of binding between MV N peptide and HSP72 (data not shown; see reference 15). The binding pattern between HSP72 and $1 \mathrm{mM}$ MV-N peptide was similar to that of HSP72 and $1 \mathrm{mM}$ p53 peptide, a positive control based upon sequences known to mediate p53-HSP72 interaction (20). Both peptides caused a change in RU on the unmodified sensor surfaces that did not change with time, a phenomenon known as bulk shift. Bulk shift simply represents the change in refractive index over the sensor that is caused by changes in buffer composition. Bulk shift was contrasted to the progressive rise in signal observed over time as MV N and p53 peptides passed over the flow channel to which HSP72 was immobilized, indicating binding. The progressive nature of binding reflected the relative excess of ligand, where binding equilibrium was not achieved. Specificity was demonstrated with MBP as analyte, where identical sensorgrams were obtained with $1 \mathrm{mM}$ peptide solution and flow channels containing no ligand or flow channels containing either HSP72 or irrelevant protein (i.e., $\operatorname{IgG}$ ) as ligand. In addition, signal over bulk shift was not observed for MV $N$ and p53 peptides passed over flow channels to which irrelevant ligand (IgG) was immobilized. While amenable to establishing specificity of binding, these reaction conditions were not suitable for determining reaction rate and equilibrium constants. The high ligand immobilization creates a mass transfer effect, where reaction rates are limited by analyte availability and not on/off rates (see Reference 30 for review).

To establish the relevance of MV $\mathrm{N}$ peptide-HSP72 interaction to MV RNP-HSP72 interaction, a binding competition assay was performed (Fig. 4). Either N peptide or MBP peptide was mixed with $1 \mathrm{nM} \mathrm{N}$ protein in the form of fragmented MV RNP, and the mixture was injected over flow channels containing HSP72. $\mathrm{N}$ peptide inhibited MV RNP binding to HSP72 in a dosagedependent manner, with 5,20 , and $50 \mu \mathrm{M}$ peptide decreasing RNP binding by 21,50 , and $63 \%$ respectively. Inhibition of RNP binding was based upon the magnitude of reduction of the maximal sensorgram response during RNP injection. Higher peptide concentrations were not employed since the optical system could directly detect peptide-HSP72 binding events in this concentration range. Sensorgrams of competitive inhibition using $5 \mu \mathrm{M}$ peptide was the most accurate reflection of RNP binding events since binding of peptide alone could not be detected. Relevance of MBP peptide-HSP72 interaction to MV RNPHSP72 interaction was not observed with 5-400 $\mu \mathrm{M}$ MBP, since $400 \mu \mathrm{M}$ MBP peptide inhibited RNP binding to HSP72 by only $18 \%$. The tremendous excess of peptide to $\mathrm{N}$ protein in these latter reactions suggests that the inhibition was non-specific.

\section{Kinetic measurements using $\mathrm{N}$ peptide}

To define the binding affinity between MV-N peptides and HSP72, we performed a kinetic analysis of the interaction using an HSP72 immobilization level of 10,000 RU (Fig. 5). This level was considered optimal based upon calculation of the maximal response of analyte to ligand $\left(\mathrm{R}_{\max }\right)$ where, for optimal kinetic analyses, the $\mathrm{R}_{\max }$ should fall within the range of 50 to $250 \mathrm{RU}$. 
The theoretical $\mathrm{R}_{\max }$ is based on the formula $\mathrm{R}_{\max }=$ $\left(\mathrm{MW}_{\mathrm{A}} / \mathrm{MW}_{\mathrm{L}}\right) \times \mathrm{R}_{\mathrm{L}} \times \mathrm{S}_{\mathrm{m}}$ where $\mathrm{MW}_{\mathrm{A}} / \mathrm{MW}_{\mathrm{L}}$ is the ratio of molecular weight of analyte to ligand, $\mathrm{R}_{\mathrm{L}}$ is the amount of ligand bound in RU, and $\mathrm{S}_{\mathrm{m}}$ represents the proposed stoichiometry of the interaction. In this case, the $\mathrm{MW}_{\mathrm{A}} / \mathrm{MW}_{\mathrm{L}}$ ratio is $1: 40$. HSP72 has only a single peptide binding site such that the $S_{m}$ equals 1 (28). Thus, the $R_{\max }$ of $250 \mathrm{RU}$ was achieved at $10,000 \mathrm{RU}$ of HSP72. Lower levels of HSP72 immobilization (i.e., ligand RU) were not used because peptide concentrations similar to the $K_{D}$ produced poor signal under these conditions, thereby limiting the range of peptide concentrations that could be analyzed. To enhance the reliability of calculated reaction constants, sensorgrams from a range of analyte concentrations should be compared, where that range encompasses the predicted $K_{D}$ for the reaction, and the results of individual sensorgrams combined in a single global analysis. The $\mathrm{K}_{\mathrm{D}}$ for HSP72 activity control binding reactions was estimated at $1-50 \mu \mathrm{M}$ based upon published data from the analysis of binding reactions with DnaK, the bacterial analogue of HSP72 (6). At 10,000 RU HSP72, we could examine binding events at $25 \mu \mathrm{M}$ peptide, a value approximating the predicted $K_{D}$, whereas peptide binding at 2,000 RU was only evident at concentrations equal to or in excess of $100 \mu \mathrm{M}$. The maximal peptide concentration that could be used for either HSP72 immobilization level was $200 \mu \mathrm{M}$. In excess of this value, sensorgrams from individual binding reactions deviated from the 1:1 Langmuir binding model, yielding unacceptably high residuals and $\mathrm{Chi}^{2}$ values, criteria used to judge the quality of fit between experimental data and that derived from binding models. Plots of residuals indicate the difference between the experimental and reference data for each point in the fit. In general, a good fit has small residuals in the -2 to +2 range that randomly distribute around the $\mathrm{x}$-axis. The $\mathrm{Chi}^{2}$ value represents the sum of squared differences between the experimental data and reference data at each data point. Typically, good fittings derive $\mathrm{Chi}^{2}$ values less than 10 . Deviation from the 1:1 model at high analyte concentration is consistent with secondary interactions that may occur between peptide analytes or between peptide and ligand. Accordingly, 10,000 RU of HSP72 supported global analysis of 4 serial 2-fold concentrations of $\mathrm{N}$ peptide $(25-200 \mu \mathrm{M})$, compared to only 2 serial 2-fold peptide concentrations at 2,000 RU HSP72, and yielded a $K_{D}=1$ with residuals between \pm 1.8 with a $\mathrm{Chi}^{2}$ value of 0.23 (Table 1). Using HSP72 immobilization levels of 20,000 $\mathrm{RU}$, we observed a similar lower limit to peptide detection, with sensorgrams from all peptide concentrations between 25 and 200 $\mu \mathrm{M}$ yielding non-randomly distributed residuals that exceed the \pm 2 range and $\mathrm{Chi}^{2}$ values in excess of 10 (Fig. 5).

\section{Structural variation in the HSP72 binding motif}

Our approach to peptide-HSP72 interaction analysis allowed us to detect differences in binding affinity for peptides incorporating one or two amino acid substitutions. For all reactions, individual sensorgrams that did not fit the 1:1 binding model were excluded from the global fit for kinetic analysis. For the parent $\mathrm{N}$ peptide, analyte concentrations of $500 \mu \mathrm{M}$ and 1 $\mathrm{mM}$ yielded a poor fit. Thus, individual curves used for the global analysis of $\mathrm{N}$ peptide-HSP72 interaction were generated by peptide concentrations of $25 \mu \mathrm{M}, 50 \mu \mathrm{M}, 100 \mu \mathrm{M}$, and $200 \mu \mathrm{M}$. The equilibrium dissociation constant thus derived was $1 \mu \mathrm{M}$, a calculated $K_{D}$ within the range reported for peptides mimicking the HSP72-interactive domain of p53 (i.e., $<200 \mu \mathrm{M}$ ) and consistent with affinity values reported for well-characterized HSP72-mediated activity control reactions (6, 20, 29). Deviation of sensorgrams from the Langmuir model at high analyte concentrations may be explained by the degree to which the $K_{D}$ is exceeded. Given the fact that an analyte concentration equal to the equilibrium constant will give $50 \%$ saturation of the surface, excessive analyte concentrations can completely saturate binding sites, promoting second-site interactions and confounding kinetic analyses. Mutant peptides included an $\mathrm{N}$ to $\mathrm{D}$ with/without an additional $\mathrm{L}$ to $\mathrm{P}$ substitution, a design based upon naturally occurring polymorphisms of MV strains. Nucleocapsid protein sequence analysis of 17 measles central nervous system isolates demonstrate that $77 \%$ harbor either $\mathrm{N}$ to $\mathrm{D}(4 \mathrm{D})$ or both $\mathrm{L}$ to $\mathrm{P}$ and $\mathrm{N}$ to $\mathrm{D}$ (3P4D) substitutions at the carboxyl terminus. A DnaK binding preference for $\mathrm{L}$ and negative bias for acidic residues is reported (18). It was therefore predicted that these amino acid substitutions would reduce HSP72 binding affinity. For mutant peptide, binding at 25 and $50 \mu \mathrm{M}$ could either not be demonstrated or resultant sensorgrams gave a poor fit to the Langmuir binding model. Curves derived from $100 \mu \mathrm{M}, 200 \mu \mathrm{M}$, $500 \mu \mathrm{M}$, and $1 \mathrm{mM}$ of mutant peptide concentrations exhibited good individual fits to the Langmuir model and were therefore subjected to global analysis. $K_{D}$ values of substituted peptideHSP72 interactions were $782 \mu \mathrm{M}$ for $4 \mathrm{D}$ and $329 \mu \mathrm{M}$ for 3P4D peptides, respectively (Table 1 ). The binding analysis showed that the basis for reduced binding affinity for these peptides was a 20 to 50 -fold slower association rate than peptide representing wild type $\mathrm{N}$ sequence and dissociation rates that were approximately 10 times faster.

Repeated analysis of peptide-HSP72 binding affinities showed minimal between-trial variation that was associated with reductions in HSP72 binding capacity with time and/or repeated use. For example, the same surface that generated a maximal response of $250 \mathrm{RU}$ for peptide binding during one trial generated a response of 210 RU after 4 days of storage, representing a 16\% decrease in HSP72 activity. Loss in binding capacity was not attributed to dissociation of ligand from the sensor surface since the baseline sensorgam values were relatively constant. The impact upon calculated binding affinity was minimal, increasing the $K_{D}$ describing $N$ peptide-HSP72 interactions to only $4 \mu \mathrm{M}$, a value that remains within the range of activity control reactions. An absolute value describing $\mathrm{N}$ peptide-HSP72 interaction is thus best represented by combining results of multiple experimental trials using freshly prepared sensor surfaces. Recognition of the limited life span of HSP72 function influenced experimental design. Analysis of mutant peptides were performed in sequence with parent peptide during the same experimental trial, where parent $\mathrm{N}$ peptide analysis both 
preceded and followed analysis of mutant peptide in order to establish the degree of variation in HSP72 binding activity. Reductions in binding capacity were negligible (i.e., $<1 \%$ ) when 3 analytes at 5 concentrations per peptide were examined. When between trial variations in HSP72 binding capacity were observed, relative differences in HSP72 binding affinity for the various peptides were maintained.

\section{Kinetic measurements using RNP}

Peptides based upon carboxyl terminal sequences of the $\mathrm{N}$ protein lack the context of the biological system, where upstream $\mathrm{N}$ protein domains and domains of neighboring $\mathrm{N}$ proteins in the RNP structure may influence HSP72 binding reactions. Binding of the $\mathrm{N}$ protein carboxyl terminus to HSP72 was thus analyzed in the context of RNP particles, comparing binding rates and affinities to those calculated using $\mathrm{N}$ peptides. The contribution of the $\mathrm{N}$ protein carboxyl terminus to RNP-HSP72 binding reactions was established using RNP composed of intact $\mathrm{N}$ protein or $\mathrm{N}$ protein in which the carboxyl terminal $15 \mathrm{kDa}$ was removed by selective proteolysis. Viral RNP was purified from the cytoplasm of infected Vero cells and a portion of the isolate subjected to treatment with Staphlococcal V8 protease. The degree to which the $\mathrm{N}$ protein was truncated as a result of this digestion was confirmed by Western blot analysis using MV N protein specific monoclonal antibody recognizing the amino terminus. The RNP helix is preserved following removal of the carboxyl terminal fragment (26), allowing direct comparison of binding reactions between parent RNP and RNP composed of truncated N proteins. For RNP-HSP72 binding affinity analysis, only 250 RU HSP72 was immobilized. The low immobilization was used so that the theoretic maximal RNP binding response would fall below 250 RU. The calculation was based on $\mathrm{R}_{\max }=$ $\left(\mathrm{MW}_{\mathrm{A}} / \mathrm{MW}_{\mathrm{L}}\right) \times \mathrm{R}_{\mathrm{L}} \times \mathrm{S}_{\mathrm{m}}$ where in this case analyte and ligand have a similar molecular weight. RNP N protein concentrations of 5 , $10,20,40$, and $80 \mathrm{nM}$ were used for a global analysis of binding reactions, again using the 1:1 Langmuir binding model. Intact RNP bound HSP72 with a $K_{D}$ equal to $16 \mathrm{nM}$ whereas cleavage of the $\mathrm{N}$ protein $\mathrm{C}$-terminus decreased RNP binding affinity for HSP72 by 27 -fold $\left(K_{D}=428 \mathrm{nM}\right)$, supporting the role of the carboxyl terminus of MV N protein in mediating RNP interactions with HSP72 (Table 2). The higher binding affinity of intact MV RNP relative to $\mathrm{N}$ peptide for HSP72 may be attributed to the multiple $\mathrm{N}$ monomers present within a given RNP fragment, all of which would participate in solid-phase HSP72 binding. Consistent with this view, the increased HSP72 binding affinity of RNP relative to peptide was due predominantly with a slower off rate, a characteristic of multivalent binding relative to monovalent interactions. It is unlikely that other protein components of the RNP preparations (i.e., $\mathrm{P}$ and $\mathrm{L}$ proteins) make significant contributions to HSP72 binding given the molar excess of $\mathrm{N}$ relative to $\mathrm{P}$ and $\mathrm{L}$ in the RNP preparations, particularly the high $\mathrm{N}: \mathrm{L}$ ratio. In addition, extensive colocalization of HSP72 and $\mathrm{N}$ within morbillivirus infected cells is contrasted to an absence of colocalization between HSP72 and P (14). The molar excess of $\mathrm{N}$ and selective colocalization of $\mathrm{N}$ and HSP72 support the conclusion that $\mathrm{N}$ protein is the predominant contributor to RNP-HSP72 binding reactions.

An alternate explanation for the relatively high affinity for RNP and HSP72 is that additional HSP72 binding sites are present on the $\mathrm{N}$ protein carboxyl terminus. Additional sites of relatively high binding affinity would explain the ability to isolate stable complexes between HSP72 and viral RNP by $\mathrm{CsCl}$ isopycnic density centrifugation $(11,12,23)$. Although the isolation procedure is adequate for the retention of viral $\mathrm{P}$ and $\mathrm{L}$ proteins on the RNP template, it is improbable that HSP72 would remain bound to a target sequence when the $\mathrm{K}_{\mathrm{D}}$ for that reaction is in the 1-4 $\mu \mathrm{M}$ range. Recent unpublished data from our laboratory support this view. Rescue of recombinant infectious virus containing either the parent Ed-MV HSP72 binding motif or the 4D-substituted motif allowed the analysis of RNP composition in cellular environments characterized by elevated HSP72 levels. RNP recovered from both viral variants exhibited stable complex formation with HSP72 despite loss of functional HSP72 responsiveness by the $4 \mathrm{D}$ variant. These results support the presence of additional HSP72 binding sites on the viral RNP, although these sites are not relevant to functional interactions mediated by the HSP72 binding motif at amino acid position 518-524 of the $\mathrm{N}$ protein. Sequence analysis of the $\mathrm{N}$ protein carboxyl terminus reveals a second putative target sequence at amino acids 495-501 (LLRLQAM), where high affinity for HSP72 is predicted. Work in progress will use BIAcore analysis to define the role of this motif in mediating RNP-HSP72 interactions.

Results of the peptide binding studies suggest that parent $\mathrm{N}$ sequences should interact functionally with HSP72 whereas mutant sequences should not. The $\mathrm{K}_{\mathrm{D}}$ 's from these analyses model monovalent interactions that would occur between RNP $\mathrm{N}$ protein constituents and HSP72 in solution (i.e., HSP72 in the soluble cell fraction). The intracellular concentration of HSP72 in the soluble cell fraction that promotes functional interactions between HSP72 and viral RNP was previously estimated to be $0.1 \mu \mathrm{M}$ (11). Since the $\mathrm{K}_{\mathrm{D}}$ describing N-HSP72 binding reactions is $1.0 \mu \mathrm{M}$, significant RNP-HSP72 interaction would be predicted within the cell, although saturation of $\mathrm{N}$ protein binding sites would be below $50 \%$.

The relationship between target sequence variation in HSP72 binding affinity and functional interactions with HSP72 was addressed in our published work using a reverse genetics system to measure HSP72-dependent changes in MV transcription and genomic replication (15). In this system, a MV transcriptional complex is reconstituted by transiently transfecting cells with plasmid constructs expressing $\mathrm{N}, \mathrm{P}, \mathrm{L}$, and a MV genome containing the CAT reporter gene. Addition of HSP72 by transfection stimulates viral transcriptional activity by 2-3 fold for wild type MV $\mathrm{N}$ as measured by CAT reporter gene expression. $\mathrm{N}$ proteins containing the C-terminal 4D and 3P4D substitutions lack a response to HSP72 supplementation. The significant loss in binding affinity between $\mathrm{N}$ protein sequences and HSP72 documented with the BIAcore system were thus correlated to 
loss of functional interactions using the reverse genetics approach.

BIAcore analysis will also be of value in identifying functionally homologous domains in related paramyxoviruses. The Onderstepoort strain of CDV has an $\mathrm{N}$ protein carboxyl terminal sequence (i.e., YSDKELL) homologous to that of the MV 4D variant since it contains a second acid side group (E) in the binding motif yet it retains HSP72 responsiveness in assays of viral transcription and genome replication (Oglesbee et al., unpublished observation). An explanation for the retention in HSP72 responsiveness can be found when the composition of the complete carboxyl terminal sequence is examined. The terminal amino acid for MV is D (i.e., YNDRNLLD) while that of CDV is $\mathrm{N}$ (i.e., YSDKELLN), making the total content of acidic side groups in the terminal 8 amino acids comparable. Preliminary studies in our laboratory have shown that $\mathrm{N}$ peptides representing the carboxyl terminal 15 amino acids of CDV and MV bind with comparable affinity, supporting the idea that binding is defined by a greater degree of primary sequence than was originally envisioned. BIAcore analysis will be ideally suited to more completely map the extent of sequences influencing functional HSP72-viral interactions, and the nature of functionally homologous motifs in other viral species.

Collectively, use of soluble peptide analytes and immobilized HSP72 in the BIAcore system allowed us to model solution interactions between HSP72 and viral RNP. The approach overcame numerous technical obstacles imposed by the insolubility of one of the binding partners (i.e., $\mathrm{N}$ protein) and the unwieldy form of the macromolecular complex formed by the $\mathrm{N}$ protein, namely the filamentous RNP helix. The result was that we were able to identify structural determinants of functional interactions between HSP72 and viral RNP. These results highlight the power of surface plasmon resonance technology in guiding molecular studies of virus-host interaction. Applications extend far beyond analysis of protein-protein and protein-peptide binding and include protein-DNA, protein-cell, and virus-cell interactions, making likely the increased use of this technology in the virology research laboratory.

\section{ACKNOWLEDGMENTS}

This work was supported by funds from the National Institute of Neurological Disorders and Stroke (R01 NS31693).

\section{REFERENCES}

1. Gething MJ, Blond-Elguindi S, Buchner J, Fourie A, Knarr G, Modrow S, Nanu L, Segal M, Sambrook J. Binding site for Hsp70 molecular chaperones in natural proteins. Cold Spring Harbour Symposia on Quantitative Biology 1995; 60:417428.

2. Gamer J, Multhaup G, Tomoyasu T, McCarty JS, Rudiger S, Schonfeld HJ, Schirra C, Bujard H, Bukau B. A cycle of binding and release of the DnaK, DnaJ and GrpE chaperones regulates activity of the Escherichia coli heat shock transcription factor sigma32. EMBO J 1996; 15(3):607-617.

3. Dunker AK, Lawson JD, Brown CJ, Williams RM, Romero P, Oh JS, Oldfield CJ, Campen AM, Rattliff CM, Hipps KW, Ausio J, Nissen MS, Reeves R, Kang C, Kissinger CR, Bailey RW, Griswold MD, Chiu W, Garner EC, Obradovic Z. Intrinsically disordered protein. J Mol Graph Model 2001; 19(1):26-59.

4. Ellis RJ, Hartl FU. Protein folding in the cell: competing models of chaperonin function. FASEB J 1996; 10(1):20-26.

5. Georgopoulos C, Liberek K, Zylicz M, Ang D. Properties of the heat shock proteins of E. coli and the autoregulation of the heat shock response. In: Morimoto R, Tissieres A, and Georgopoulos C, (Eds.). The biology of the Heat Shock Proteins and Molecular Chaperones. Cold Spring Harbour Laboratory Press 1994; 209-250.

6. de Crouy-Chanel A, Kohiyama M, Richarme G. Interaction of DnaK with native proteins and membrane proteins correlates with their accessible hydrophobicity. Gene 1999; 230(2):163-170.

7. Vasconcelos DY, Cai XH, Oglesbee MJ. Constitutive overexpression of the major inducible $70 \mathrm{kDa}$ heat shock protein mediates large plaque formation by measles virus. $J$ Gen Virol 1998; 79:2239-2247.

8. Andrews JM, Newbound GC, Oglesbee MJ, Brady JN, Lairmore MD. The cellular stress response enhances human T-cell lymphotropic virus type 1 basal gene expression through the core promoter region of the long terminal repeat. J Virol 1997; 71(1):741-745.

9. Alfano C, McMacken R. Heat shock protein-mediated disassembly of nucleoprotein structures is required for the initiation of bacteriophage lambda DNA replication. $J$ Biol Chem 1989; 64(18):10709-10718.

10. Oglesbee MJ, Kenney H, Kenney T, Krakowka S. Enhanced production of morbillivirus gene-specific RNAs following induction of the cellular stress response in stable persistent infection. Virol 1993; 192(2):556-567.

11. Oglesbee MJ, Liu Z, Kenney H, Brooks CL. The highly inducible member of the $70 \mathrm{kDa}$ family of heat shock proteins increases canine distemper virus polymerase activity. J Gen Virol 1996; 77:2125-2135.

12. Oglesbee MJ, Ringler S, Krakowka S. Interaction of canine distemper virus nucleocapsid variants with $70 \mathrm{~K}$ heat shock protein. J Gen Virol 1990; 71:1585-1590.

13. Oglesbee MJ, Tatalick L, Rice J, Krakowka S. Isolation and characterization of canine distemper virus nucleocapsid variants. J Gen Virol 1989; 70:2409-2419.

14. Oglesbee MJ, Krakowka S. Cellular stress response induces selective intranuclear trafficking and accumulation of morbillivirus major core protein. Lab Invest 1993; 68:109-117.

15. Zhang X, Glendening C, Linke H, Parks CL, Brooks C, Udem SA, Oglesbee M. Identification and characterization of a regulatory domain on the carboxyl terminus of the measles virus nucleocapsid protein. J Virol 2002; 76(17):8737-8746.

16. Blond-Elguindi S, Cwirla SE, Dower WJ, Lipshutz RJ, Sprang SR, Sambrook JF, Gething MJ. Affinity panning of a 
library of peptides displayed on bacteriophages reveals the binding specificity of BiP. Cell 1993; 75(4):717-728.

17. Longhi S, Receveur-Bréchot V, Karlin D, Johansson K, Darbon H, Bhella D, Yeo R, Finet S, Canard B. The Cterminal domain of the measles virus nucleoprotein is intrinsically disordered and folds upon binding to the Cterminal moiety of the phosphoprotein. I Biol Chem 2003; 278(20):18638-18648.

18. Rudiger S, Germeroth L, Schneider-Mergener J, Bukau B. Substrate specificity of the DnaK chaperone determined by screening cellulose-bound peptide libraries. EMBO J 1997; 16(7):1501-1507.

19. Burkholder WF, Zhao X, Zhu X, Hendrickson WA, Gragerov A, Gottesman ME. Mutations in the C-terminal fragment of DnaK affecting peptide binding. Proc Natl Acad Sci USA 1996; 93(20):10632-10637.

20. Fourie AM, Hupp TR, Lane DP, Sang BC, Barbosa MS, Sambrook JF, Gething MJ. Hsp70 binding sites in the tumor suppressor protein P53. J Biol Chem 1997; 272(31):1947119479.

21. Mannie MD, Paterson PY, U'Prichard DC, Flouret G. Induction of experimental allergic encephalomyelitis in Lewis rats with purified synthetic peptides: delineation of antigenic determinants for encephalitogenicity, in vitro activation of cellular transfer, and proliferation of lymphocytes. Proc Natl Acad Sci USA 1985; 82(16):55155519.

22. Mustafa MM, Weitman SD, Winick NJ, Bellini WJ, Timmons CF, Siegel JD. Subacute measles encephalitis in the young immunocompromised host: report of two cases diagnosed by polymerase chain reaction and treated with ribavirin and review of the literature. Clin Infect Dis 1993; 16(5):654-660.

23. Vasconcelos D, Norrby E, Oglesbee M. The cellular stress response increases measles virus-induced cytopathic effect. $J$ Gen Virol 1998; 79:1769-1773.

24. Lund GA, Tyrrell DL, Bradley RD, Scraba DG. The molecular length of measles virus RNA and the structural organization of measles nucleocapsids. J Gen Virol 1984; 65:1535-1542.

25. Oglesbee M, Tatalick L, Ringler S, Rice J, Krakowka J. Rapid isolation of morbillivirus nucleocapsid for genomic RNA cDNA cloning and the production of specific core protein antisera. J Virol Methods 1989; 24:285-300.

26. Giraudon P, Jacquier MF, Wild TF. Antigenic analysis of African measles virus field isolates: identification and localisation of one conserved and two variable epitope sites on the NP protein. Virus Res 1988; 10(2-3):137-152.

27. Misselwitz B, Staeck O, Matlack KE, Rapoport TA. Interaction of $\mathrm{BiP}$ with the J-domain of the Sec63p component of the endoplasmic reticulum protein translocation complex. J Biol Chem 1999; 274(29):2011020115.

28. Bukau B, Horwich AL. The Hsp70 and Hsp60 chaperone machines. Cell 1998; 92(3):351-366.

29. Fourie AM, Sambrook JF, Gething MJ. Common and divergent peptide binding specificities of hsp70 molecular chaperones. J Biol Chem 1994; 269(48):30470-30478.

30. Myszka DG. Kinetic analysis of macromolecular interactions using surface plasmon resonance biosensors. Curr Opin Biotechnol 1997; 8:50-57. 


\section{FIGURES AND TABLES}

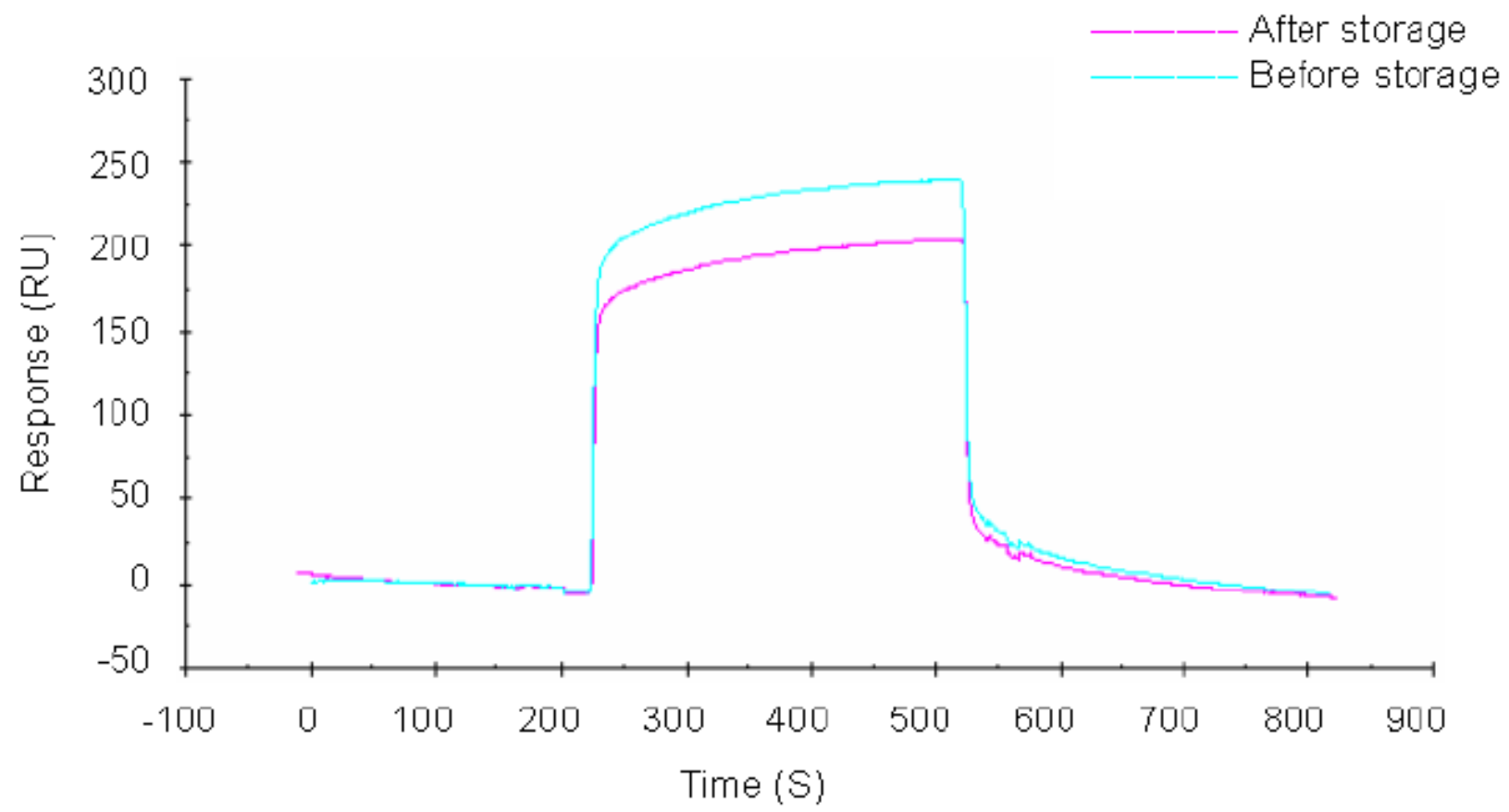

Fig. 1: BIAcore 3000 sensorgrams demonstrating a decline in HSP72 binding capacity as a function of chip storage. HSP72 was immobilized on a CM5 chip at $20,000 \mathrm{RU}$, where $1,000 \mathrm{RU}=1 \mathrm{ng} / \mathrm{mm}^{2}$ of HSP72 on the surface. Interaction between $200 \mu \mathrm{M} \mathrm{N}$ peptide and HSP72 was indicated by a change in RU over the course of the $300 \mathrm{~s}$ injection interval. The same sensor surface after $4 \mathrm{~d}$ of storage at $4^{\circ} \mathrm{C}$ gave rise to a maximal response that was 40 RU less than that generated in the previous trial when binding with freshly prepared peptide solution was examined, representing a 16\% decrease in HSP72 binding capacity. The loss in binding capacity did not reflect loss of HSP72 from the sensor surface, based upon lack of change in the baseline sensorgram readings.

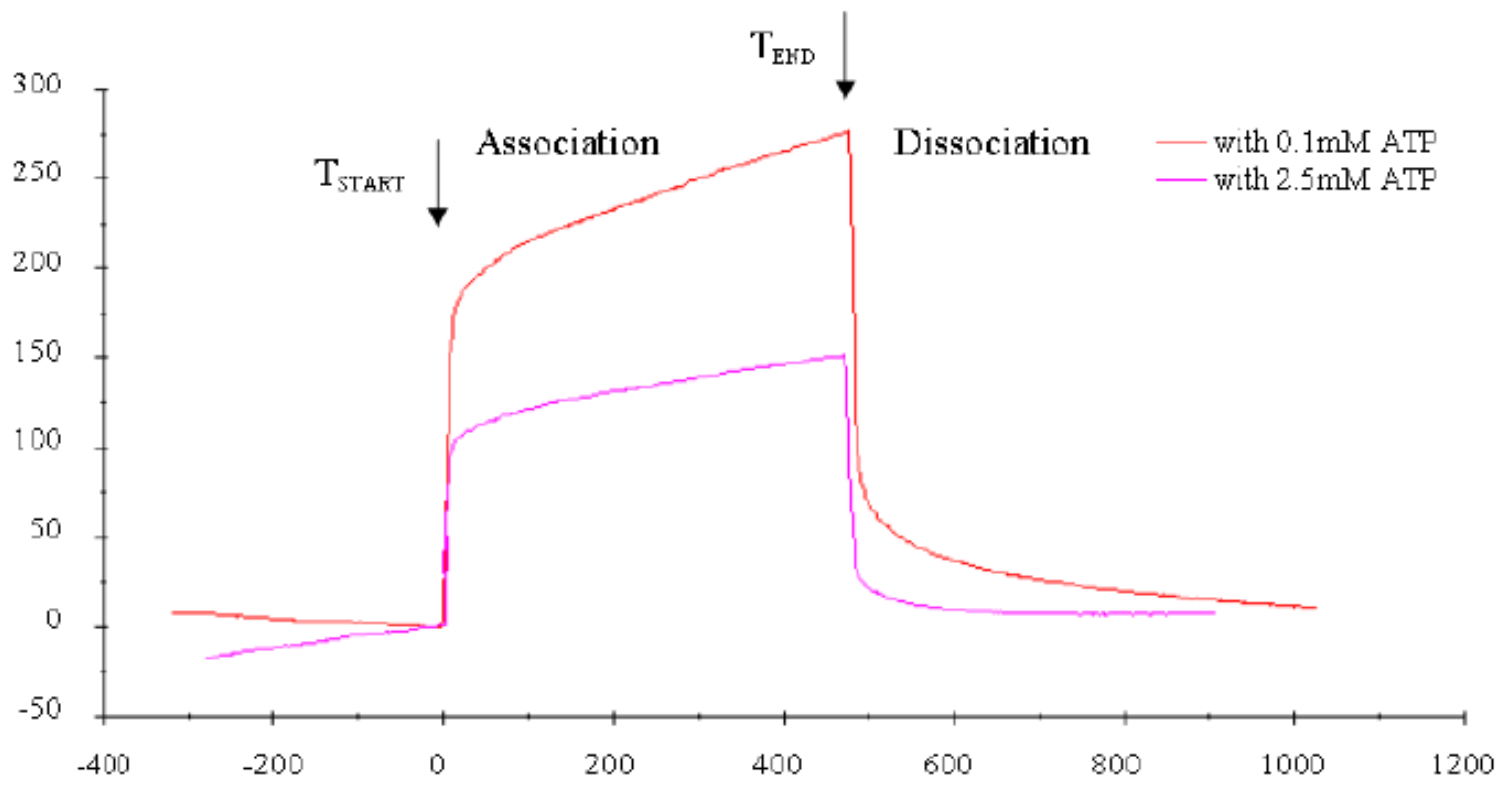

Time (S)

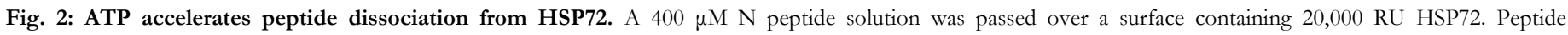

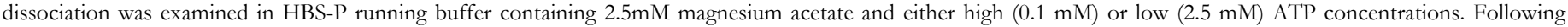

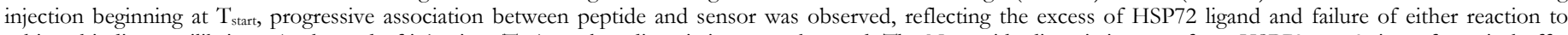

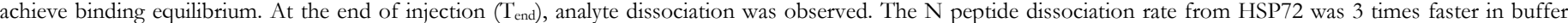

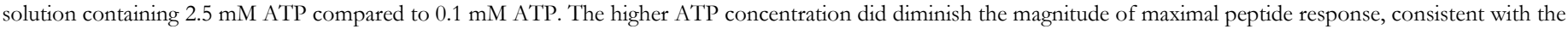


role of ATP in promoting HSP72-substrate dissociation.
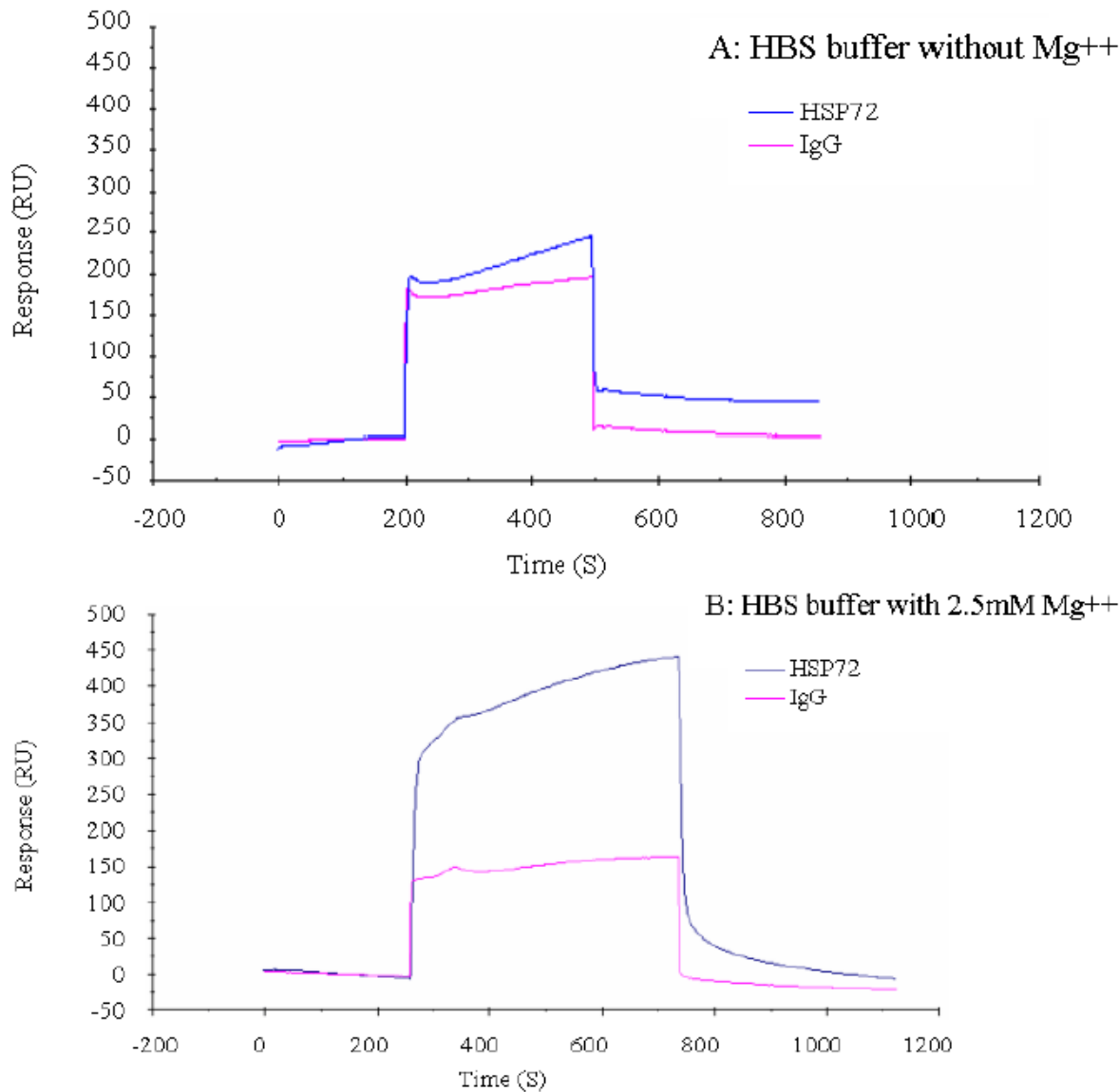

Fig. 3: Mg++ selectively enhances peptide binding for HSP72 but not irrelevant ligand. (A) Four hundred $\mu \mathrm{M} N$ peptide was passed over sensors containing either 20,000 RU HSP72 or an irrelevant ligand ( $\mathrm{ggG}$ ) to which peptide binding was not predicted. Reaction buffer lacked $\mathrm{Mg}^{++}$. At the end of injection, the magnitude of the N Peptide-HSP72 binding response was 40 RU higher than the maximal peptide-IgG interaction. The IgG and HSP72 immobilization levels were comparable although not identical, differing by a factor of 3. (B) Binding in HBS buffer with $2.5 \mathrm{mM}$ magnesium acetate and $400 \mu \mathrm{M}$ peptide showed no change in the peptideIgG interaction whereas peptide-HSP72 binding was greatly enhanced, yielding a response $250 \mathrm{RU}$ above the peptide-IgG interaction.

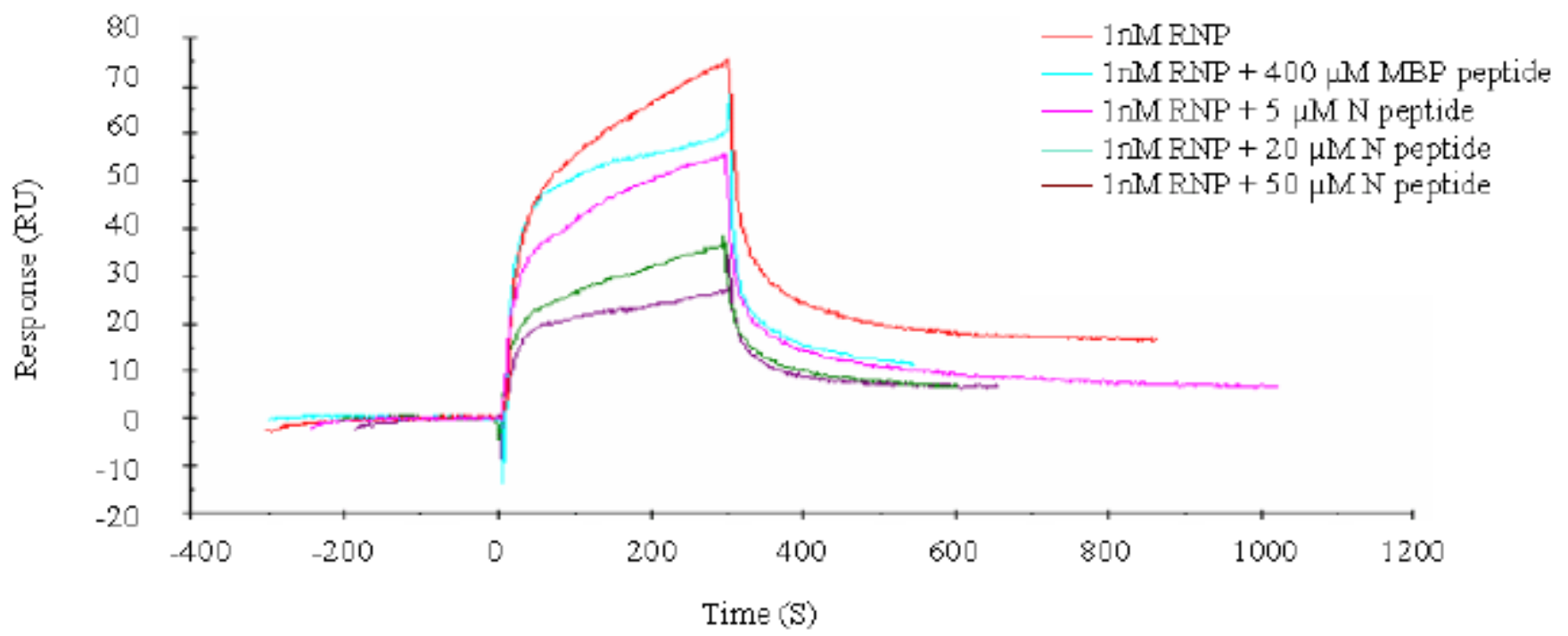

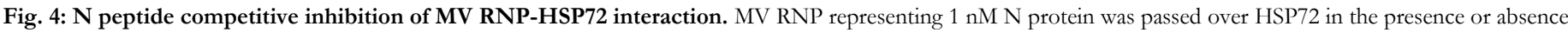

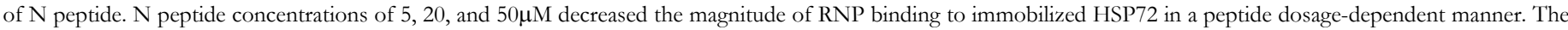

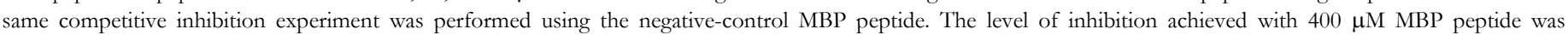


comparable to that using only $5 \mu \mathrm{M}$ N peptide.

A: $10.000 R$ USP72
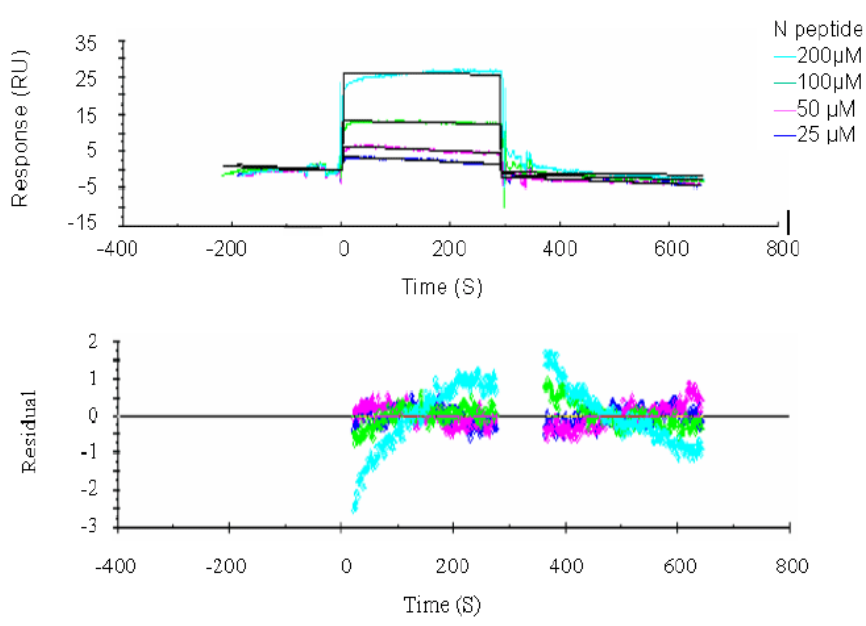

B: $20.000 R U$ HSP72
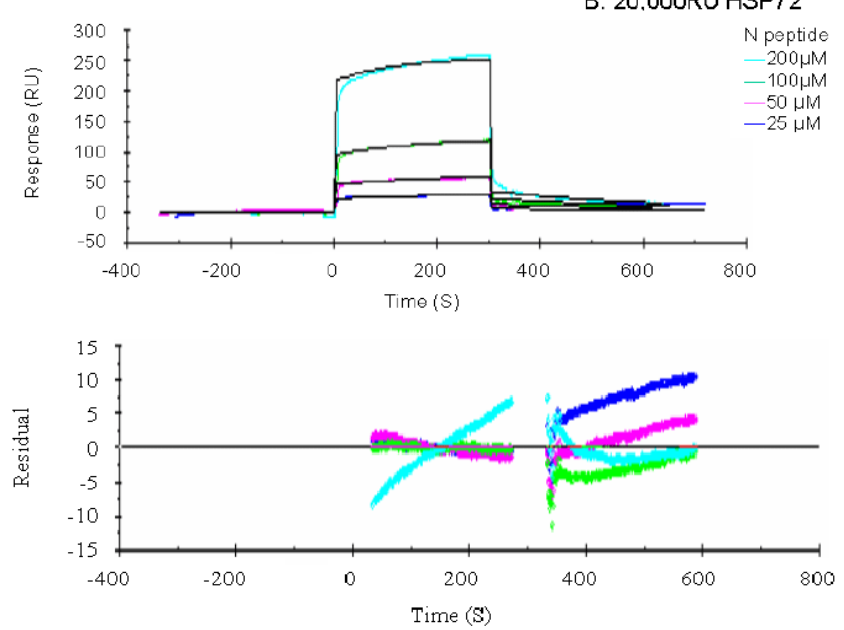

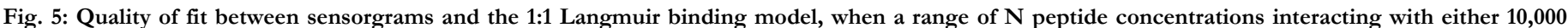

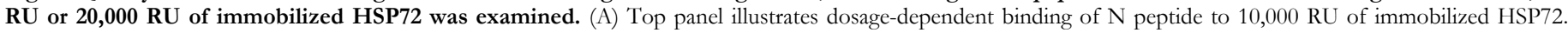

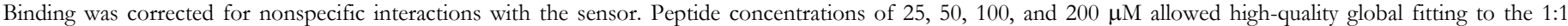

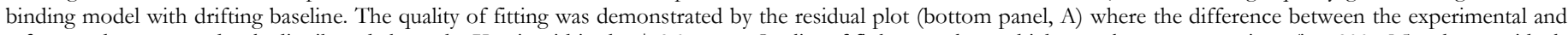

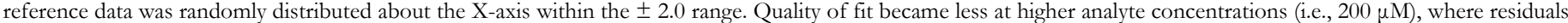



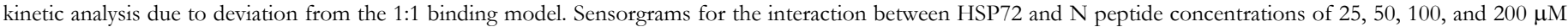
yielded residuals that exceeded the \pm 2 range and were consistently curvilinear (i.e., non-randomly distributed along the $\mathrm{X}$-axis), regardless of peptide concentration.

Table 1: Sensorgrams for the interaction between HSP72 and N peptide concentrations of 25, 50, 100, and $200 \mu \mathrm{M}$ allowed high-quality global fitting to a 1:1 Langmuir binding model. Calculated equilibrium dissociation constants $\left(K_{D}\right)$, on rate $\left(k_{a}\right)$, and off rate $\left(k_{d}\right)$ are shown. High-quality global fitting for N4D and N3P4D peptide was based upon sensorgrams generated with 100, 200, 500, and $1000 \mu \mathrm{M}$ peptide concentrations. The HSP72 immobilization level was 10,000 RU.

\begin{tabular}{|c|c|c|c|c|c|}
\hline \multirow{2}{*}{ Peptide Analyte } & \multicolumn{2}{|c|}{ Quality of Fit } & \multirow{2}{*}{$\begin{array}{c}\mathbf{k}_{\mathrm{a}} \\
(1 / \mathrm{Ms})\end{array}$} & \multirow{2}{*}{$\begin{array}{c}k_{d} \\
(1 / s)\end{array}$} & \multirow{2}{*}{$\begin{array}{c}\mathrm{K}_{\mathrm{D}} \\
(\mu \mathrm{M})\end{array}$} \\
\hline & Residuals & $\mathrm{Chi}^{2}$ & & & \\
\hline $\mathrm{N}$ & $-1.8-1.8$ & 0.23 & 357 & $4.1 \times 10-4$ & 1 \\
\hline N4D & $-1.0-1.6$ & 0.09 & 7 & $5.5 \times 10-3$ & 782 \\
\hline N3P4D & $-1.0-2.1$ & 0.22 & 14 & $4.4 \times 10-3$ & 329 \\
\hline
\end{tabular}

Table 2: Sensorgrams for the interaction between HSP72 and RNP N protein concentrations of 5, 10, 20, 40, and 80 nM allowed high-quality global fitting to a 1:1 Langmuir binding model, allowing the computation of $\mathrm{K}_{\mathrm{D}}$ and association and dissociation rate constants $\mathrm{k}_{\mathrm{a}}$ and $\mathrm{k}_{\mathrm{d}}$. This binding reaction was compared to that of RNP subject to selective proteolysis with Staphylococcus aureus V8 protease.

\begin{tabular}{lccccc}
\hline Analyte & \multicolumn{2}{c}{ Quality of Fit } & $\mathbf{k}_{\mathbf{a}}$ & \multicolumn{1}{c}{$\mathbf{k}_{\mathbf{d}}$} & \multicolumn{2}{c}{} \\
& Residuals & $\mathbf{C h i}^{2}$ & $(\mathbf{1} / \mathbf{s})$ & $1 \times 10^{-5}$ & 16 \\
RNP & $-1.5-1.5$ & 0.32 & 643 & 23 & $1 \times 10^{-5}$ \\
RNP + V8 & $-1.0-1.0$ & 0.22 & 23 & 428 \\
\hline
\end{tabular}

